\title{
Unique Id Generation for Citizens with Extended Security
}

\author{
Nayana B P1, M. S Satyanarayana ${ }^{2}$ and Pankaja $\mathrm{R}^{3}$ \\ ${ }^{1}$ Department of Information Science \& Engineering, Sri \\ Venkateshwara College of Engineering, Bengaluru, India \\ ${ }^{2}$ Department of Information Science \& Engineering, Sri Venkateshwara \\ College of Engineering, Bengaluru, India \\ ${ }^{3}$ Department of Information Science \& Engineering, Sri Venkateshwara \\ College of Engineering, Bengaluru, India
}

\section{ABSTRACT}

Population is the one parameter which grows day by day in any country, to maintain the data of each and every human being is very important as it is needed in future either for medical or legal reasons. So, it is always suggested to have the data of the people in proper format so that when it is needed it can be make use of. The developed countries like United States of America using Social Security Number and developing countries like India making use of Aadhar Number as reference to know about the citizens. The main problem is most of the developed countries are maintaining $80 \%$ accurate data, but the developing countries like India still there are some loopholes with respect to the unique numbers awarded to citizens because with single number not able to fetch all data. In this paper the unique number generation and also the secured way of using it when needed for know your customer kind of activities will be done securely and the people get trust while using the number and another main advantage of this unique number is to remember and recollect. This number can be used any location both for Identity, Financial Transactions etc

\section{KEY WORDS: AADHAR NUMBER, SOCIAL SECURITY NUMBER, MEDICAL, LEGAL, UNIQUE NUMBER.}

\section{INTRODUCTION}

Unique Number is an need of any country to know more about the citizens of the country where they are residing and also when citizens travel to other countries, they will be identified with the same number to check whether he is a genuine citizen of that particular country or not. Apart from this the data of a human being will be very

\section{ARTICLE INFORMATION}

*Corresponding Author: nayananavi@gmail.com

Received 9th Oct 2020 Accepted after revision 27th Dec 2020

Print ISSN: 0974-6455 Online ISSN: 2321-4007 CODEN: BBRCBA

Thomson Reuters ISI Web of Science Clarivate Analytics USA and Crossref Indexed Journal

\section{Clarivate
Analytics}

NAAS Journal Score 2020 (4.31)

A Society of Science and Nature Publication,

Bhopal India 2020. All rights reserved.

Online Contents Available at: http//www.bbrc.in/

Doi: http://dx.doi.org/10.21786/bbrc/13.13/30 much essential to know about the history of particular person. The information of a particular person includes Credit History, Medical History, Legal History, Educational details etc.., the unique id should be generated to each and every person at the time of birth and for the existing people it should be generated very effectively like tying up the all said data of the person in step by step manner. This is the one of the step which needs to be followed when generating the unique ID for a person. The actual problem is remembering this number and sometimes this number will be given to multiple users or same user is having multiple numbers. Both the ways it is very difficult to handle this kind of scenarios.

In this paper, the procedure followed to generate unique ID is very unique in nature and all data can be secured under this id. And people can easily remember the ID. No need to generate every time OTP to do the Know

$$
214
$$


Your Customer (KYC) process. It will be done with the kind of Psychometric test to the users every time for the security purpose (K. Prakasha, B. Muniyal and V. Acharya, 2019).

Illustration: The existing unique ID's are though they are covering piece of information about that particular person but they are not effective because in most of the countries it is just used as an identity proof and it is not fully digitalized, because of which every time the person has to submit copy of this document to the corresponding activity and also to verify the data the person has to do it with OTP. Sometimes due to network issue or if the user forgot his mobile number or lost his mobile number every time, he needs to update it.

It is a tedious process then what is the solution, the solutions is very simple the unique id should be fully digital and it should not depend only on the OTP which the person receives it should purely depends on the person who created it. If there occurs any problem, the person has to go to the concern department to get it corrected. Currently in developing countries different unique ID's are used for different purposes like Voter ID, Driving License etc.., Here the problem is how many numbers a person can remember and also every time verification is tedious process. So, to overcome this problem the proposed method will be used (S. Patil, A. Bansal, U. Raina, V. Pujari and R. Kumar, 2018).

Existing System: In existing system, the unique ID is generated randomly in India which is called as Aadhar Number and it is shown as one identity proof but nowhere it is for financial and legal transactions, and every time when the identity needs to be verified the OTP will come to user which needs to be given to vendor. Sometimes if the particular user lost his mobile which he gave at the time of registration again he need approach nearby center and then provide details it will take minimum 10 to 15 days to update it. And not all the data of the user is available with this Aadhar Number every time user has to link it with Voter ID, PAN, Driving License etc. again the user has to remember multiple numbers which is a tedious process.

In the existing system though, there are few advantages like,

- Unique ID generated for every individual

- It can be used as unique ID proof.

- It is an ID where the 50\% of user information available.

The major disadvantages are,

- Manual verification every time using OTP.

- It can be used only in India.

- It is just an identity proof.

- Modifications in the user profile is tedious process.

Proposed Method and Procedure of Id Genration: In the proposed way of unique ID generation each and every aspect of a human being is been covered like his financial, legal and medical information. This ID will be generated for newly born immediately in the hospital itself there on they can start using it. The data will be stored when and where there is an update. This will be linked for every activity the person do so that the data will be up to date. To give an example, if a kid born immediately, he will be assigned with a unique ID. When particular kid is taking vaccine, the same unique ID will be attached and it will store the information of the particular kid what are the vaccine he has taken. Then later when kid want to join school the kid will be joined based on the ID generated. And the process continues in every scenario (R. Padmavathi, K. M. M. Azeezulla, P. Venkatesh, K. K. Mahato and G. Nithin , 2017).

If the ID needs to be generated for the adults, they should follow some procedure.

Pseudo Code for Generation of Unique ID for adults.

- Generate Unique ID for the person but don't activate it.

- $\quad$ Give that ID to the person as a reference.

- Ask the person to go the different departments like Police, Medical, Legal departments to attach this unique ID with his records.

- The third step is one-time process in whole life.

- Once it done the ID will be activated.

- $\quad$ The ID can be used for further needs.

Unique Id Format: As another issue in current ID is remembering the ID maybe it is 12 digits or 14 digits. In proposed methodology the unique ID will start from 20 Digits to 25 Digits still people can easily remember it. The unique identification number mainly consists of the following parameters and it is customizable means the parameters can be interchanged as per the need of the customers. The key parameters to be considered in generating unique ID are.
1. DOB of the Father
2. DOB of the mother
3. DOB of the person
4. DOB of the partner.
5. DOB of the kids (optional))
6. Location of Creation
7. Time of creation

Are the different parameters used for unique ID generation? And the id is going to be minimum of 20 to 25 digits and it is very difficult to guess by anyone. And the security parameters are location and time of creation which needs to be remembered by the user exactly. Because date of birth of any family member can be remembered very easily but the time of creation and location of creation is very important. As per the research made on $10000+$ samples of data not even one single number is repeated, if it repeats also the time and location will be changed including for twins. So, the possibility of getting same unique id for more than one person is very difficult. Once the unique id is generated in order to avoid the OTP process at the time of creation and sometimes if needed few questions need to be answered by the user starting from minimum 10 questions to $n$ number of questions. The number of questions increases the security of storing of information about a person (C. 
S. P. Varma, D. S. Rahul, J. Jose, B. K. Samhitha and S. C. Mana, 2020).

Why These Questions?: The questions will be asked to record the answers and at the time of any transactions and data submissions the same questions will be popped up for the user to answer on given time to complete the required task. The question may arise what about computer illiterate, for them the process will be carried out it. The person who is accessing it needs to be authenticated so as to avoid illegal transactions.

So, the overall security depends on the user how they are going to maintain it further so no need to trust anybody while doing transactions and no need to face any technical glitches in getting OTP etc... The time of creation for the ID will be taken as per the system time in 4-digit format so that for twins also there will be at least one-minute gap while creating it. And coming to the location, there will be one location database which will be maintained by providing the unique id for each and every place for example the code will be generated based on the following elements

1. Country

2. State

3. District

4. Place

These 4 parameters will be considered while generating id these data can be very easy for any person to remember. Here the idea is to choose either the location or id created or place of birth. Likewise, the id will be created and stored entire information about the person and verified when and where it is needed (Vishal, V. Chinmay, R. Garg and P. Yadav, 2016).

Implementation: To implement this system first the id, need to be generated once it is done the questions will be attached to the ID then it will go for testing phase the entire data provided by the user will be cross checked from each and every department once it is confirmed then the Id will! Let's consider a scenario to understand the prices very easily if a person is generating id it will ask for date of births as per parameter mentioned and records the current time and location will be taken as input from user for the accuracy.

\section{Example:}

Person date of birth is $31 / 03 / 1986$

Mother Date of Birth is 05/04/1964

Father Date of Birth is 07/06/1961

Then the initial unique id of the person will be

\section{1}

The format of the date of birth can be changed based on the country. As a second step the time of registration need to be recorded it will be as per the system time on 24hours scale. Let's say for example if the time of registration is 13:30 PM then the ID will become

\section{0}

And the third step is location from where registration is done, it will be purely depends on the Country Number, State, District and Place. To give an example let us consider India, in India we have following States. Initially the countries data will be taken as Likewise, the country list goes on, the specified country will be selected from this list, based on the country selected further states data will be selected, The states data will be stored as follows in order to pick the right state from the particular country. Let us consider an example if the selected country is India then code becomes

Table 1. Country ID

\begin{tabular}{|l|c|}
\hline Country Id & Country Name \\
\hline C1 & India \\
\hline C2 & USA \\
\hline C3 & Singapore \\
\hline C4 & Switzerland \\
\hline
\end{tabular}

$3103198605041964070619611330 \mathrm{C} 1$

And the states lists are as follows

Table 2. State ID

\begin{tabular}{|c|c|}
\hline State Id & State Name \\
\hline S1 & Karnataka \\
\hline S2 & Andhrapradesh \\
\hline S3 & Tamilnadu \\
\hline S4 & Kerala \\
\hline
\end{tabular}

Consider if the person is from Karnataka then the ID will become $3103198605041964070619611330 \mathrm{C} 1 \mathrm{~S} 1$

And the districts in Karnataka will be considered further,

Table 3. District ID

\begin{tabular}{|l|c|}
\hline District Id & District Name \\
\hline D1 & Bengaluru \\
\hline D2 & Tumkur \\
\hline D3 & Hassan \\
\hline D4 & Kolar \\
\hline
\end{tabular}

If suppose the person is from Kolar district then the unique ID will become 3103198605041964070619611330C1S1D4

In kolar again based on the place where he is from the id will be generated, consider for example

Suppose if person is from Mulbagal then the unique id will become 


\section{C1S1D4L3}

Table 4. Location ID

\begin{tabular}{|l|c|}
\hline Location Id & Location Name \\
\hline L1 & Kolar Town \\
\hline L2 & Chintamani \\
\hline L3 & Mulbagal \\
\hline L4 & Hoskote \\
\hline
\end{tabular}

Now the final id generated is of 35 character sizes still the people can easily remember, while displaying in the virtual platform the masked id will be displayed. Where the security data will be masked and that needs to be remembered by the user. Consider the above example the masked ID will be

Original ID:

3103198605041964070619611330C1S1D4L3

Masked ID:

310319860504196407061961XXXXXXXXXXXX

So, the final id will be known only to the user who created it and it can be used wherever it is needed and no need to submit any copy of this to any department because every time secure authentication will be done by the user itself.

Questions: The questions which are going to be stored along with ID will be generic in nature where the answer will be known only to the person who created it, the number of questions are getting increased the security will Also increase; as system will pick questions randomly the user can feel the security and user also have option to modify this question once in 3 months in order to increase the security.

The sample set of questions are as follows

- What is your pastime activity?

- Which place do u like most?

- What is your goal?

- What is the first mobile number you used?

- What is the name of car you want to own?

Likewise, questions can be created by the user and answer will be stores, these will be asked at the time of verification. The main advantage in this system is user only creating his account, and user is deciding what the level of security he wants is. So, user cannot blame any system or department with respect to security. Apart from this if the system gets doubt to do double check any time the unique ID system popup questions from the unique ID like what is the time you created your ID with time limitation and also the system checks for whether the user is the right user by asking multiple question with time bound. For example, from the above example system may ask questions like
- What is your date of birth last digit 198_?

- Time of creation Second digit 1_:30?

- Are you from Karnataka? Yes: No

Likewise, multiple number of questions will be generated and kept ready to cross check the user, And similar questions will be considered which doing any financial transaction instead of sending OTP these questions will be populated once the user answers correctly the transaction will be done if the user fails to answer any one question the entire the transaction will be cancelled. So, this system is secured proof because the user is sole responsible for their own security and no need to wait OTP and signal issues etc.., end of the day how best and possible security will be decided by the user.

\section{RESULTS}

The final results will be the unique ID generated for each and every user which can be used virtually for any of the activities like Ticket Booking, Buying Insurance, getting insurance claimed, getting driver's license etc.., once the ID is generated the same will be used everywhere so tracking individual will be very easy and also if the person travelling to other country easy to identify which country he belongs to and same number can be used for any transactions the person is going to make. Because of which if there Is any fraudulent transactions found is to identify the person wherever he is and also the person will have freedom to know which department is working and which department is not replying properly.

Figure 1: Format 1 for ID Generation

\begin{tabular}{|l|l|l|l|l|l|l|}
\hline USER & WOTHER & FATHER & MTME OF & LOCATION OF & Best Friend & Farcáte \\
DOB & DOB & DOB & REGISTRATION & REGISTRATION & DOB & Color \\
\hline
\end{tabular}

These methods most of the corruption will be avoided as the maximum process will be done using virtual platform. The unique structure of the unique ID generated will be as follows

Figure 2: Format 2 for ID Generation

\begin{tabular}{|l|l|l|l|l|}
\hline USER & MOTHER & FATHER & FMIE OF & LOCATION OF \\
DOB & DOB & DOB & REGISTRATION & REGISTRATION \\
\hline
\end{tabular}

It is the basic idea by which the ID will be generated apart from this the system can be made complex many more fields by which it is very difficult to hack the data for the hackers but the users can easily. Remember the ID's. After doing extensive research on this Idea later the team included few more parameters to make this ID complex for other to remember and the user can still remember very easily. So, the Complexity and security purely depends on the country where this ID will be generated and also the user who is going to use it.

Comparision With Existing System: The proposed method when compare to existing method there are so many advantages and very minimal disadvantages as well. Advantages: 
- Unique ID generations are so easy and meaningful.

- No need of every time OTP, instead the system will use psychometric question to identify user.

- Easily user can perform financial and legal activities with security.

- One number for all needs, no need to remember multiple numbers.

Disadvantages: This not exactly drawback with respect to technology, it is an implementation issue that is attaching all existing details to Unique ID especially for the Adults will take some extra time compare to the children.

\section{CONCLUSION}

By considering all above scenarios it is concluded that generation of Unique ID for any citizen should be dynamic in nature. Security is purely depends on the person who is going to generate this ID and also the government based on the strict rules they follow in implementing this system as a mandatory process. If this system is implemented fault proof surely it will bring the value to the country by protecting their citizen's data in proper format by providing the required services.

Future Enhancement: In future this system will be integrated with an application, which will be specific to this number which can be used anywhere any time so that it will be possible to provide extended security to the users.

\section{REFERENCES}

C. S. P. Varma, D. S. Rahul, J. Jose, B. K. Samhitha and S. C. Mana (2020) "Aadhar Card Verification Base Online Polling," 2020 4th International Conference on Trends in Electronics and Informatics (ICOEI)(48184), Tirunelveli, India, 2020, pp. 479-483

K. Prakasha, B. Muniyal and V. Acharya (2019), "Automated User Authentication in Wireless Public Key Infrastructure for Mobile Devices Using Aadhar Card," in IEEE Access, vol. 7, pp. 17981-18007.

R. Padmavathi, K. M. M. Azeezulla, P. Venkatesh, K. K. Mahato and G. Nithin 2017, "Digitalized Aadhar enabled ration distribution using smart card," 2017 2nd IEEE International Conference on Recent Trends in Electronics, Information \& Communication Technology (RTEICT), Bangalore, 2017, pp. 615-618.

S. Patil, A. Bansal, U. Raina, V. Pujari and R. Kumar 2018, "E-Smart Voting System with Secure Data Identification Using Cryptography," 2018 3rd International Conference for Convergence in Technology (I2CT), Pune, 2018, pp. 1-4.

Vishal, V. Chinmay, R. Garg and P. Yadav (2016), "Online voting system linked with AADHAR," 2016 3rd International Conference on Computing for Sustainable Global Development (INDIACom), New Delhi, 2016, pp. 3239-3240. 